\title{
Bumnerodoey open Impact of COVID-19 pandemic on stroke admissions in Qatar
}

\author{
Naveed Akhtar, ${ }^{1}$ Salman Al Jerdi, ${ }^{2}$ Ziyad Mahfoud, ${ }^{2}$ Yahia Imam, ${ }^{1}$ Saadat Kamran, ${ }^{1}$ \\ Maher Saqqur, ${ }^{3}$ Deborah Morgan, ${ }^{1}$ Sujatha Joseph, ${ }^{1}$ Khurshid Khan, ${ }^{3}$ \\ Ashfaq Shuaib $^{3}$
}

To cite: Akhtar N, Al Jerdi S, Mahfoud Z, et al. Impact of COVID-19 pandemic on stroke admissions in Qatar. BMJ Neurology Open 2021;3:e000084. doi:10.1136/ bmjno-2020-000084

Received 23 July 2020 Revised 01 December 2020 Accepted 07 December 2020

Check for updates

(c) Author(s) (or their employer(s)) 2021. Re-use permitted under CC BY-NC. No commercial re-use. See rights and permissions. Published by BMJ.

${ }^{1}$ The Neuroscience Institute, Hamad Medical Corporation, Doha, Qatar

${ }^{2}$ Weill Cornell Medical College, Doha, Qatar

${ }^{3}$ University of Alberta, Edmonton, Alberta, Canada

Correspondence to

Dr Ashfaq Shuaib;

ashfaq.shuaib@ualberta.ca

\begin{abstract}
Introduction The COVID-19 pandemic has resulted in a dramatic unexplained decline in hospital admissions due to acute coronary syndromes and stroke. Several theories have emerged aiming to explain this decline, mostly revolving around the fear of contracting the disease and thus avoiding hospital visits.

Aims In this study, we aim to examine the impact of the COVID-19 pandemic on stroke admissions to a tertiary care centre in Qatar.

Methods The Hamad General Hospital stroke database was interrogated for stroke admissions between September 2019 and May 2020. The number of stroke admissions, stroke subtypes and short-term outcomes was compared between the 'pre-COVID-19' period (September 2019 to February 2020) and the COVID-19 pandemic period (March to May 2020).

Results We observed a significant decline in monthly admissions in March (157), April (128) and May (135) compared with the pre-COVID-19 6-month average (229) $(p=0.024)$. The reduction in admissions was most evident in functional stroke mimics. The average admissions decreased from 87 to 34 per month $(p=0.0001)$. Although there were no significant differences in admissions due to ischaemic stroke (IS), intracranial haemorrhage or transient ischaemic attacks between the two periods, we noted a relative decrease in IS due to small vessel disease and an increase in those due to large vessel atherosclerosis in March to May 2020.

Conclusions The decline in overall stroke admissions during the COVID-19 pandemic is most likely related to concerns of contracting the infection, evidenced mainly by a decline in admissions of stroke mimics. However, a relative increase in large vessel occlusions raises suspicion of pathophysiological effects of the virus, and requires further investigation.
\end{abstract}

\section{INTRODUCTION}

During the outbreak of Middle East respiratory syndrome in South Korea in 2015, there was a striking decrease in low-acuity disease presentations $(45.2 \%)$ to emergency departments (EDs). In addition, a lesser but notable decrease in visits due to stroke $(16.6 \%)$ and myocardial infarction $(14 \%)$ occurred. ${ }^{1}$ Similar declines in admissions of non-vascular illnesses, stroke and cardiovascular disease have also been observed in EDs during the recent COVID-19 pandemic. $^{2}$ The number of cardiac catheterisation laboratory ST-segment elevation myocardial infarction activations decreased by $38 \%$ in the USA and $40 \%$ in Spain as the pandemic spread. ${ }^{3} 4$ There was also a reported decline in the number of strokes in Piacenza, a city of 280000 inhabitants and an important epicentre of the disease in Northern Italy, with monthly admissions decreasing from an average of 51 cases to only 6 over a 5 -week period. ${ }^{5}$ Two larger studies from China and Spain also reported an estimated $25 \%$ decrease in patients who had a stroke presenting to EDs during the peak weeks of the pandemic. ${ }^{6}{ }^{7}$ Moreover, two recent reports from the USA and Brazil report a decrease in transient ischaemic attacks (TIAs) and minor strokes during the pandemic. ${ }^{89}$

Although the decrease in minor ailments and trauma-related ED visits may be due to a fear of exposure to the virus, the reasons behind the significant drops in visits due to major acute cardiovascular and cerebrovascular events remain unclear. Paradoxically, recent reports are beginning to highlight an association between COVID-19 and a heightened coagulation state, resulting in an increased risk of severe stroke in younger patients. ${ }^{10}$

Prospective hospital-based or community registries are critical when studying the effects of pandemics on the rates of admissions due to vascular diseases. ${ }^{11}$ Registries may also provide important insights pertaining to time-sensitive healthcare delivery metrics, such as door-to-intervention times, and shed light on treatment delays real time, as was recently observed in the treatment of myocardial infarctions in Hong Kong. ${ }^{12}$ Similarly, concerns over delays in timesensitive management of ischaemic stroke during the COVID-19 pandemic continue to increase. 


\section{AIMS AND OBJECTIVES}

The Qatar Stroke Database has prospectively collected detailed information on stroke admissions to Hamad General Hospital (HGH) for 7 years. ${ }^{13}{ }^{14}$ To evaluate the impact of COVID-19 on stroke care in Qatar, we interrogated the HGH database for admissions and healthcare delivery metrics over the last 4 months of 2019 and the first 5 months of 2020. Our main objective was to compare the change in the rate of admissions of patients who had a stroke. We also aimed to explore any differences in stroke subtypes and short-term outcomes before and during the pandemic.

\section{METHODS}

The Qatar Stroke Database prospectively collects information on all patients who had an acute stroke admitted to the HGH in Qatar. The hospital has a dedicated stroke ward, admits $98 \%$ of patients who had a stroke in Qatar and is the only centre where treatment with intravenous thrombolysis and mechanical thrombectomy is offered. The details of the database have previously been published. ${ }^{1314}$

\section{Patient and public involvement}

This study does not come under patient and public involvement criteria. Patients or the public were not involved in the design of this study.

\section{Data sharing}

Relevant anonymised patient-level data can be made available on further request.

All patients who had a stroke admitted to HGH from September 2019 to May 2020 were evaluated for this study. Clinical information including rates of admissions, clinical presentation, National Institutes of Health Stroke Scale (NIHSS) at admission and discharge, Trial of Org 10172 in Acute Stroke Treatment (TOAST) classification, ethnicity, risk factors, investigations, complications, length of stay and discharge outcomes was obtained. ${ }^{15}$ The modified Rankin Scale (mRS) before admission, at discharge and at 90-day follow-up was also collected when available.

Monthly stroke admission rates to HGH were evaluated for the last 4 months in 2019, prior to the onset of COVID-19 pandemic, and were compared with the first 5 months of 2020. We investigated these rates as the pandemic was being documented in China and Europe (January to February), and as COVID-19, cases began to be diagnosed in Qatar (March to May). In addition to overall rates of admissions, we evaluated the frequency of stroke subtypes, TIAs and stroke mimics during the study period. We documented all patients diagnosed with COVID-19.

Descriptive and inferential statistics were used to characterise the study sample. Descriptive results (including graphical displays) for all quantitative variables (eg, age) are presented as the mean \pm SD for normally distributed data or median with IQR for data not normally distributed.

The monthly rate of stroke admissions was compared in the 6 months pre-COVID-19 to 3 consecutive months of COVID-19 pandemic using the Mann-Whitney U test, and using the Poisson test with the outcome being the observed count in the 3 months post-COVID-19 and assuming that the previous 6-month rate was the average prior to COVID-19. The monthly rate of stroke mimics was compared between the pre-COVID-19 period and the post-COVID-19 period in a similar manner. Bivariate analysis comparing the demographic and clinical characteristics of the patients along with some discharge outcomes between the two periods was performed using independent samples t-test, and the Mann-Whitney U test to compare the average for all quantitative variables (eg, age) between stroke subtypes, wherever appropriate, while the Pearson $\chi^{2}$ test or Fisher's exact test was used, as appropriate, in comparing all the qualitative variables. The statistical tests were performed using IBM SPSS Statistics V.26 (IBM). A p value of 0.05 or less was considered significant.

\section{RESULTS}

Over the 9-month study period, 1796 patients (age: 53.0 \pm 14.2 ; male/female: 1318 (73.4\%)/478 (26.6\%)) were admitted to HGH's stroke service (table 1). The higher percentage of males reflects the demographics of Qatar with a predominantly male expatriate population. The first confirmed COVID-19 case in Qatar was reported on 27 February 2020. In March, April and May, the monthly reported cases of COVID-19 were 779, 12628 and 45501, respectively. There were 1376 admissions in the 6 months prior to the local COVID-19 spread (average monthly admissions to HGH: 229, see table 1). With the increase in confirmed COVID-19 cases in the country, there was a significant decrease in the rates of hospital admissions for suspected stroke to an average of 140 per month (March: 157; April: 128; May: 135, $\mathrm{p}=0.024$ using Mann-Whitney $\mathrm{U}$ test and $\mathrm{p}<0.001$ using the Poisson test, see figure 1). Except for age, there were no significant differences in the demographics and comorbidities between patients who were admitted pre-COVID-19 period and those admitted post-COVID-19 period (see table 1).

The rates of ischaemic strokes and intracerebral haemorrhage increased significantly from the pre-COVID to the post-COVID time period $(41.6 \%-53.6 \%, \mathrm{p}<0.001$ and $8.1 \%-12.9 \%, p=0.003$, respectively), while those of stroke mimics decreased significantly from $38.0 \%$ to $24.0 \%$, $\mathrm{p}<0.001$; whereas the minimal changes in the rates of TIAs and cerebral venous sinus thrombosis did not reach statistical significance between the two time periods.

When considered per month, the average number of stroke mimics, including medical and functional, in the initial 6 months was 87 . This decreased significantly to 34 in the last 3 months (March: 46; April: 27; May: 28, 
Table 1 Baseline characteristics and investigations of patients during the pre-COVID period and the post-COVID period

\begin{tabular}{|c|c|c|c|c|c|c|c|}
\hline \multirow[b]{2}{*}{$\begin{array}{l}\text { Characteristic or } \\
\text { investigation }\end{array}$} & Total & \multirow{2}{*}{$\begin{array}{l}\text { Pre-COVID time } \\
\text { (September } \\
2019 \text { to } \\
\text { February 2020) } \\
\text { (n=1376, } \\
\text { average=229.3 } \\
\text { per month) }\end{array}$} & \multirow{2}{*}{$\begin{array}{l}\text { COVID } \\
\text { time } \\
\text { (March } \\
2020) \\
\\
(n=157) \\
\end{array}$} & \multirow{2}{*}{$\begin{array}{l}\text { COVID } \\
\text { time (April } \\
2020) \\
\\
(n=128) \\
\end{array}$} & \multirow{2}{*}{$\begin{array}{l}\text { COVID } \\
\text { time (May } \\
2020) \\
\\
(n=135)\end{array}$} & \multirow{2}{*}{$\begin{array}{l}\text { Post-COVID } \\
\text { time } \\
\text { (March to } \\
\text { May 2020) } \\
\\
(n=420) \\
\end{array}$} & \multirow[b]{2}{*}{$P$ value } \\
\hline & $(n=1796)$ & & & & & & \\
\hline Age, mean (years) & $53.0 \pm 14.2$ & $52.5 \pm 14.0$ & $54.5 \pm 14.8$ & $54.6 \pm 14.4$ & $54.9 \pm 15.0$ & $54.7 \pm 14.7$ & $0.007^{*}$ \\
\hline Sex (males) & $1318(73.4)$ & $1010(73.4)$ & $115(73.2)$ & $89(69.5)$ & $104(77.0)$ & $308(73.3 .0)$ & 0.978 \\
\hline Sec (females) & $478(26.6)$ & $366(26.6)$ & $42(26.8)$ & $39(30.5)$ & $31(23.0)$ & $112(26.7)$ & \\
\hline Hypertension & $1181(65.8)$ & $904(65.7)$ & $118(75.2)$ & 90 (70.3) & $69(51.1)$ & $277(66.0)$ & 0.923 \\
\hline Diabetes & $838(46.7)$ & $626(45.5)$ & $83(52.9)$ & $62(48.4)$ & $67(49.6)$ & $212(50.5)$ & 0.073 \\
\hline Dyslipidaemia & $928(51.7)$ & 701 (50.9) & 99 (63.1) & $70(54.7)$ & $58(43.0)$ & $227(54.0)$ & 0.265 \\
\hline Coronary artery disease & 195 (10.9) & $142(10.3)$ & $21(13.4)$ & $13(10.2)$ & $19(14.1)$ & $53(12.6)$ & 0.185 \\
\hline $\begin{array}{l}\text { Atrial fibrillation on } \\
\text { admission }\end{array}$ & $126(7.0)$ & $99(7.2)$ & $12(7.6)$ & $5(3.9)$ & $10(7.4)$ & $27(6.4)$ & 0.590 \\
\hline History of stroke & $202(11.2)$ & $153(11.1)$ & $21(13.4)$ & $13(10.2)$ & $15(11.1)$ & $49(11.7)$ & 0.756 \\
\hline Active smoking & $415(23.1)$ & $331(24.1)$ & $34(21.7)$ & $27(21.1)$ & $23(17.0)$ & $84(20.0)$ & 0.084 \\
\hline \multicolumn{8}{|l|}{ Final diagnosis } \\
\hline Ischaemic stroke & 797 (44.4) & $572(41.6)$ & 79 (50.3) & 72 (56.3) & $74(54.8)$ & $225(53.6)$ & $<0.001^{*}$ \\
\hline $\begin{array}{l}\text { Transient ischaemic } \\
\text { attack }\end{array}$ & $192(10.7)$ & $157(11.4)$ & $14(8.9)$ & $16(12.5)$ & $5(3.7)$ & $35(8.3)$ & 0.074 \\
\hline Intracerebral haemorrhage & 165 & $111(8.1)$ & $16(10.2)$ & $11(8.6)$ & $27(20.0)$ & $54(12.9)$ & $0.003^{*}$ \\
\hline $\begin{array}{l}\text { Cerebral venous sinus } \\
\text { thrombosis }\end{array}$ & $18(1.0)$ & $13(0.9)$ & $2(1.3)$ & $2(1.6)$ & $1(0.7)$ & $5(1.2)$ & 0.587 \\
\hline Stroke mimic & $624(34.7)$ & $523(38.0)$ & 46 (29.3) & $27(21.1)$ & $28(20.7)$ & $101(24.0)$ & $<0.001^{*}$ \\
\hline \multicolumn{8}{|l|}{ TOAST classification } \\
\hline Small vessel disease & 336 (41.2) & $258(44.1)$ & 38 (46.9) & 25 (33.8) & $15(20.0)$ & 78 (33.9) & $0.008^{*}$ \\
\hline Large vessel disease & $141(17.3)$ & $84(14.4)$ & $17(21.0)$ & $24(23.0)$ & $16(21.3)$ & $57(24.8)$ & $<0.001^{*}$ \\
\hline Cardioembolic & $215(26.4)$ & $151(25.8)$ & $17(21.0)$ & $17(23.0)$ & $30(40.0)$ & $64(27.8)$ & 0.557 \\
\hline $\begin{array}{l}\text { Stroke of determined } \\
\text { origin }\end{array}$ & $43(5.3)$ & $32(5.5)$ & $3(3.7)$ & $3(4.1)$ & $5(6.7)$ & $11(4.8)$ & 0.693 \\
\hline $\begin{array}{l}\text { Stroke of undetermined } \\
\text { origin }\end{array}$ & $80(9.8)$ & 60 (10.3) & $6(7.4)$ & $5(6.8)$ & $9(12.0)$ & $20(8.7)$ & 0.500 \\
\hline \multicolumn{8}{|l|}{ Prognosis-at discharge } \\
\hline Good (mRS 0-2) & $1246(69.4)$ & 997 (72.5) & $97(61.8)$ & $76(59.4)$ & 76 (56.3) & 249 (59.3) & $<0.001^{*}$ \\
\hline Poor (mRS 3-6) & $550(30.6)$ & $379(27.5)$ & $60(38.2)$ & $52(40.6)$ & $59(43.7)$ & $171(40.7)$ & \\
\hline Mortality - at discharge & $23(1.3)$ & $15(1.1)$ & $2(1.3)$ & $2(1.6)$ & $4(3.0)$ & $8(1.9)$ & 0.194 \\
\hline NIHSS on admission & $3.9 \pm 6.1$ & $3.6 \pm 5.9$ & $4.4 \pm 5.7$ & $5.3 \pm 6.7$ & $6.0 \pm 7.4$ & $5.2 \pm 6.6$ & $<0.001^{*}$ \\
\hline $\begin{array}{l}\text { Mild stroke (NIHSS } 4 \text { or } \\
\text { less) }\end{array}$ & $1347(75.0)$ & $1071(77.8)$ & $111(70.7)$ & $84(65.6)$ & $81(60.0)$ & $276(65.7)$ & $<0.001^{*}$ \\
\hline $\begin{array}{l}\text { Moderate stroke (NIHSS } \\
5-10)\end{array}$ & 227 (12.6) & 155 (11.3) & $23(14.6)$ & 25 (19.5) & $24(17.8)$ & $72(17.1)$ & $0.002^{*}$ \\
\hline $\begin{array}{l}\text { Severe stroke (NIHSS } \\
>10)\end{array}$ & $222(12.4)$ & $150(10.9)$ & $23(14.6)$ & $19(14.8)$ & $30(22.2)$ & $72(17.1)$ & $0.001^{*}$ \\
\hline
\end{tabular}

${ }^{*}$ Significant $p$ values.

mRS, modified Rankin Scale; NIHSS, National Institutes of Health Stroke Scale; TOAST, Trial of Org 10172 in Acute Stroke Treatment. 


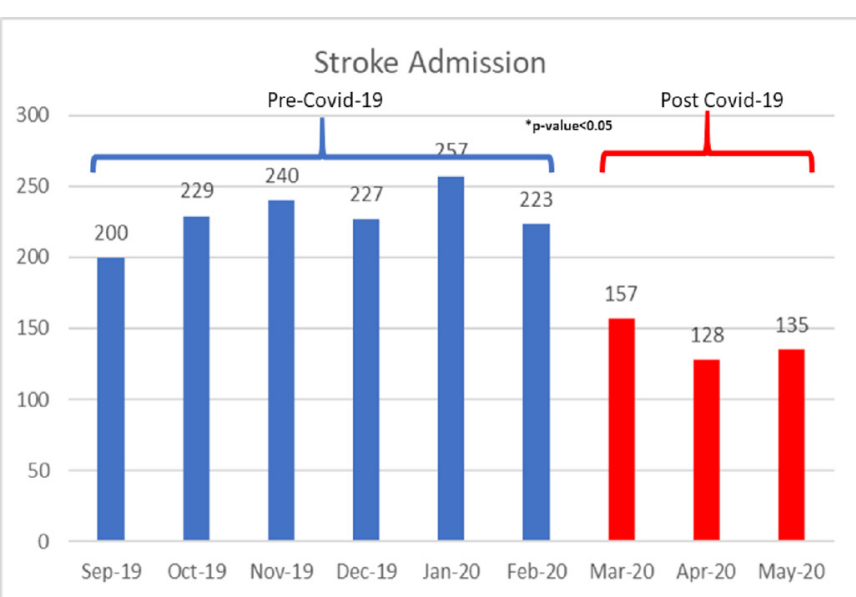

Figure 1 Number of patients admitted to the Hamad General Hospital in Qatar every month during the 6 months prior to the first reported case of COVID-19 (September 2019 to February 2020) and the 3 months when COVID-19 cases were being reported (March to May 2020). There is a significant decrease in the overall stroke admissions during the post-COVID-19 period $(\mathrm{p}<0.05)$.

$\mathrm{p}=0.024$ using Mann-Whitney $\mathrm{U}$ test and $\mathrm{p}<0.001$ using the Poisson test) (see figure 2).

TOAST criteria were used for classifying the aetiology of ischaemic stroke in our patients. ${ }^{15}$ Small vessel disease (SVD) is the most common type of stroke in the Qatari and expatriate population, likely due to the high prevalence of poorly controlled hypertension and diabetes. ${ }^{14}$ There was a significant decrease in the percentage of SVD in patients with confirmed ischaemic stroke, decreasing from $44.1 \%$ in the preceding 6 months to $33.9 \%$ in the 3 months post-COVID-19 $(\mathrm{p}=0.008)$. We also noted a concomitant significant increase in the percentage of stroke due to large vessel disease, increasing from $14.4 \%$ in the 6 months pre-COVID- 19 to $24.8 \%$ in the 3 months

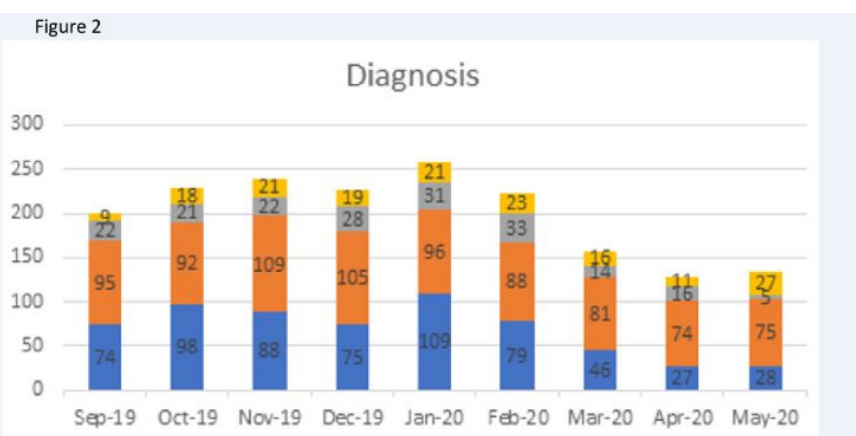

$$
\begin{aligned}
& \text { - }=\text { STROKE MIMIC } \\
& \text { ISANAEMIENT ISCHAEMIC ATTACK } \\
& \text { INTRACEREBRAL HAEMORRHAGE }
\end{aligned}
$$

Figure 2 The number of admissions of ischaemic stroke, transient ischaemic attacks, intracerebral haemorrhage and stroke mimics in Qatar 6 months prior to COVID-19 and during pandemic. The significant decrease in the number of suspected stroke admissions during March to May 2020 is related to a decrease in stroke mimics.
post-COVID-19 (21\% in March, 23\% in April and 21.3\% in May, $\mathrm{p}<0.001)$.

The severity of symptoms at presentation increased during the pandemic months. There was an increase in the average NIHSS on admission from $3.6 \pm 5.9$ in the 6 months pre-COVID to $5.2 \pm 6.6$ in the 3 months postCOVID (4.4 \pm 5.7 in March, 5.3 \pm 6.7 in April and 6.0 \pm 7.4 in May, $\mathrm{p}<0.001)$. The percentage of patients with mild symptoms (NIHSS <4) decreased from $77.8 \%$ in the preCOVID months to $65.7 \%$ in the 3 months post-COVID-19 (70.7\% in March, $65.6 \%$ in April and $60.0 \%$ in May, $\mathrm{p}=0.0001)$.

Finally, there was a decrease in the number of patients with good outcomes at discharge. The percentage of patients with mRS 0-2 at discharge decreased from $72.5 \%$ in the pre-COVID months to $59.3 \%$ in the 3 months postCOVID (61.8\% in March, $59.7 \%$ in April and $56.3 \%$ in May, $\mathrm{p}=0.0001)$. Although mortality increased a little from $1.1 \%$ pre-COVID to $1.9 \%$ post-COVID, this increase did not reach statistical significance $(\mathrm{p}=0.194)$ (table 1$)$.

\section{DISCUSSION}

The Qatar Stroke Database was established in 2013 and has shown a steady rise in stroke admissions over the past 7 years. This trend exhibits seasonal variations, manifesting in relative increases during the spring and summer months. ${ }^{13} 1416$

Only a single patient was diagnosed with COVID-19 in Qatar in February 2020, with the number of cases increasing significantly in March, April and May. Our study demonstrated a significant decrease in the rate of overall admissions of patients with suspected stroke during those 3 months. The decreases appear to be driven primarily by a reduction in the number of stroke mimics. In addition, we noted a relative decrease in strokes related to SVD and a reciprocal increase in strokes due to large vessel atherosclerosis. This was mirrored by an increased severity of symptoms at admission and lower rates of good outcomes at discharge. We did not have 90-day follow-up of mRS data available at the time of writing this manuscript.

Several reasons may underlie this apparent decrease in admissions and relative change in causative pathophysiology. First, the decrease in stroke mimics, both medical and functional, strongly suggests a reluctance to seek medical attention for fear of contracting the virus. This concern may have also driven patients with stroke causing minor neurological deficits, most of which are likely due to SVD, from seeking treatment at an outpatient setting or avoiding it entirely. This trend appears to parallel those of many countries around the world, and includes other serious conditions such as cardiac and surgical emergencies. ${ }^{571217-19}$

Second, the variation in the number of large vessel strokes with more significant deficits may be related to pathophysiological changes induced by SARS-CoV-2. Recent reports have highlighted the association of COVID-19 with more severe strokes, the latter occasionally being the 
presenting feature, especially in younger patients often without other notable risk factors. ${ }^{10}$ An increase in lupus anticoagulant and other abnormal coagulation tests may also be more commonly seen in patients with COVID-19 and may be linked to the higher incidence of strokes. ${ }^{20}$

Our study has several strengths. The Qatar Stroke Database has been accurately recording an increase in stroke admissions over the past 7 years until the months of the pandemic. A noticeable decline occurred over the March to May 2020 period, which coincided with a dramatic increase in the number of COVID-19 cases reported in the country. We were able to demonstrate that this decline in admissions was mostly driven by a decrease in stroke mimics, especially those with underlying functional aetiologies. Our results are consistent with admission data observed in many parts of the world.

The study also has some limitations. The study period included only a 3-month duration of the COVID-19 pandemic, which may not be enough to completely examine the changes in admissions or fully document the impact of the pandemic. Given the time of this study, we also do not have complete follow-up data on patients seen during the pandemic, which prevented us from adequately examining usual 90 -day outcomes.

The impact of COVID-19 in our communities in general and patients who had a stroke in particular cannot be overstated. Further studies are required to completely understand its magnitude and challenges, and to clarify the best mechanisms of addressing them.

\section{Twitter Salman Al Jerdi @AlJerdi}

Contributors Concept, design and draft: NA, AS. Acquisition, analysis, interpretation of data, technical and administrative support: NA, SK, YI, MS, SAJ, DM, SJ. Critical review: KK, ZM, SAJ. Statistical analysis: ZM.

Funding We received a generous grant from Hamad Medical for the ethics approved study (1616/16) from which these data were derived.

Competing interests None declared.

Patient consent for publication Not required.

Ethics approval The study has been approved by the Institutional Review Board at the Medical Research Centre (MRC) (file number 16016/16) and the HGH Research Committee.

Provenance and peer review Not commissioned; externally peer reviewed.

Data availability statement All data relevant to the study are included in the article or uploaded as supplementary information. If required, any further data can be made available on reasonable request.

Open access This is an open access article distributed in accordance with the Creative Commons Attribution Non Commercial (CC BY-NC 4.0) license, which permits others to distribute, remix, adapt, build upon this work non-commercially, and license their derivative works on different terms, provided the original work is properly cited, appropriate credit is given, any changes made indicated, and the use is non-commercial. See: http://creativecommons.org/licenses/by-nc/4.0/.

\section{REFERENCES}

1 Lee SY, Khang YH, Lim HK. Impact of the 2015 middle East respiratory syndrome outbreak on emergency care utilization and mortality in South Korea. Yonsei Med J 2019;60:796-803.

2 Thornton J. Covid-19: A\&E visits in England fall by $25 \%$ in week after lockdown. BMJ 2020;369:m1401.

3 Garcia S, Albaghdadi MS, Meraj PM. Reduction in ST-segment elevation cardiac catheterization laboratory activations in the United States during COVID-19 pandemic. JACC.

4 Rodríguez-Leor O, Cid-Alvarez B, Ojeda S. Impacto de la pandemia de COVID-19 sobre la actividad asistencial en cardiología ntervencionista en España. REC Interv Cardiol 2020.

5 Morelli N, Rota E, Terracciano C, et al. The Baffling case of ischemic stroke disappearance from the casualty department in the COVID-19 era. Eur Neurol 2020;83:213-5.

6 Zhao J, Li H, Kung D, et al. Impact of the COVID-19 epidemic on stroke care and potential solutions. Stroke 2020;51:1996-2001.

7 Montaner J, Barragán-Prieto A, Pérez-Sánchez S, et al. Break in the stroke chain of survival due to COVID-19. Stroke2020;51:2307-14.

8 Siegler JE, Heslin ME, Thau L, et al. Falling stroke rates during COVID-19 pandemic at a comprehensive stroke center. J Stroke Cerebrovasc Dis 2020;29:104953.

9 Diegoli H, Magalhães PSC, Martins SCO, et al. Decrease in hospital admissions for transient ischemic attack, mild, and moderate stroke during the COVID-19 era. Stroke 2020;51:2315-21.

10 Oxley TJ, Mocco J, Majidi S, et al. Large-Vessel stroke as a presenting feature of COVID_19 in the young. N Engl J Med 2020;382:e60.

11 Alger HM, Williams JH, Walchok JG, et al. Role of data registries in the time of COVID-19. Circulation 2020;13.

12 Tam C-CF, Cheung K-S, Lam S, et al. Impact of coronavirus disease 2019 (COVID-19) outbreak on ST-segment-elevation myocardial infarction care in Hong Kong, China. Circulation 2020;13:e006631.

13 Akhtar N, Kamran S, Singh R, et al. Beneficial effects of implementing stroke protocols require establishment of a geographically distinct unit. Stroke 2015;46:3494-501.

14 Akhtar N, Salam A, Kamran S, et al. Ethnic variation in acute cerebrovascular disease: analysis from the Qatar stroke Registry. Eur Stroke J 2016;1:231-41.

15 Adams HP, Bendixen BH, Kappelle LJ, et al. Classification of subtype of acute ischemic stroke. definitions for use in a multicenter clinical trial. TOAST. Trial of Org 10172 in acute stroke treatment. Stroke 1993;24:35-41.

16 Salam A, Kamran S, Bibi R, et al. Meteorological factors and seasonal stroke rates: a four-year comprehensive study. J Stroke Cerebrovasc Dis 2019;28:2324-31.

17 Kansagra AP, Goyal MS, Hamilton S, et al. Collateral effect of Covid-19 on stroke evaluation in the United States. N Engl J Med 2020;383:400-1.

18 Patriti A, Eugeni E, Guerra F. What happened to surgical emergencies in the era of COVID-19 outbreak? considerations of surgeons working in an Italian COVID-19 red zone. Updates Surg 2020;72:309-10.

19 De Filippo O, D'Ascenzo F, Angelini F, et al. Reduced rate of hospital admissions for ACS during Covid-19 outbreak in northern Italy. $N$ Engl J Med 2020;383:88-9.

20 Bowles L, Platton S, Yartey N, et al. Lupus anticoagulant and abnormal coagulation tests in patients with Covid-19. N Engl J Med 2020;383:288-90. 